\title{
Triphenylmethanol and
}

\section{Tris(2-(hydroxymethyl)phenol) Derivatives: Synthesis and Application as Indicators for Acid-Base Volumetric Titration}

\author{
Ryan Beni ${ }^{1,2}{ }^{*}$, William Boadi', Jawzah Alnakhli', Samiyah Alhamed', Tiffany Robinson', \\ Melanie Mootry ${ }^{1}$, Nahom Iyob ${ }^{1}$, Jamill Jackson ${ }^{1}$, Natalie Spicer ${ }^{1}$, Anterrial Harris ${ }^{1}$, \\ Ibrahim Bamidad1, Renner Antwi1, Shania Richardson', Tralynn Williams² \\ ${ }^{1}$ Department of Chemistry, Tennessee State University, Nashville, TN, USA \\ ${ }^{2}$ Department of Chemistry, Columbus State University, Columbus, GA, USA \\ Email: *ybeni@tnstate.edu
}

How to cite this paper: Beni, R., Boadi, W., Alnakhli, J., Alhamed, S., Robinson, T., Mootry, M., Iyob, N., Jackson, J., Spicer, N., Harris, A., Bamidad, I., Antwi, R., Richardson, S. and Williams, T. (2019) Triphenylmethanol and Tris(2-(hydroxymethyl)phenol) Derivatives: Synthesis and Application as Indicators for Acid-Base Volumetric Titration. Journal of Analytical Sciences, Methods and Instrumentation, 9, 13-21.

https://doi.org/10.4236/jasmi.2019.92002

Received: April 19, 2019

Accepted: June 2, 2019

Published: June 5, 2019

Copyright () 2019 by author(s) and Scientific Research Publishing Inc. This work is licensed under the Creative Commons Attribution International License (CC BY 4.0).

http://creativecommons.org/licenses/by/4.0/

cc) (7) Open Access

\begin{abstract}
Polyphenols are naturally occurring compounds found largely in fruits, vegetables, cereals and beverages. Currently, there is much interest in the potential health benefits of dietary plant polyphenols as antioxidants. The effect of polyphenols on human cancer cells is most often protective and induces a reduction in the number of tumors or rate of growth. During our course of study on anticancer prodrugs, twelve triphenylmethanol and one tris(2-(hydroxymethyl) phenol derivatives were synthesized as a carrier of several drugs with optimized lipophilicity. Besides application of these compounds as a foundation for anticancer drug delivery systems, these compounds were evaluated as indicators for the acid-base volumetric titration of a standard solution of hydrochloric acid with a standard solution of sodium hydroxide. The experiments indicated a moderate-to-sharp color transition of the solutions near the neutralization point for most indicators. These indicators may have potential applications for acid-base titrations in a narrow range.
\end{abstract}

\section{Keywords}

Polyphenols, Triphenylmethanol, Acid-Base Indicators, Volumetric Titration, Neutralization

\section{Background and Introduction}

An acid-base indicator is a weak acid or a weak base. Any substance that under- 
goes a reversible chemical change when $\mathrm{pH}$ changes can be used as an acid-base indicator. However, a sharp change in color of the substance is required. The undissociated form of the indicator is a different color from the ionic form of the indicator. An Indicator does not change color from pure acid to pure alkaline at specific hydrogen ion concentration, but rather, a color change occurs over a range of hydrogen ion concentrations. This range is termed as the color change interval. It is expressed as a $\mathrm{pH}$ range.

There are several reports about household materials that can be used as acid/base indicators [1] [2] [3] [4] [5]. Most of these materials are natural products derived from plants and so-called phenolic antioxidants. Polyphenols are naturally occurring compounds found largely in fruits, vegetables, cereals and beverages. Fruits like grapes, apples, pears, cherries and berries contain up to 200 $300 \mathrm{mg}$ of polyphenols per 100 grams fresh weight [6] [7] [8]. In the last decade, there has been much interest in the potential health benefits of dietary plant polyphenols as antioxidants. The effect of polyphenols on human cancer cells is most often protective and induces a reduction in the number of tumors or rate of growth. These effects have been observed at various sites including the mouth, stomach, duodenum, colon, liver, lungs, mammary glands and skin. Many polyphenols, such as quercetin, catechins, isoflavones, lignans, flavanones, ellagic acid, red wine polyphenols, resveratrol and curcumin have been tested; all of them showed protective effects in some models although their mechanisms of action were found to be different. [9] [10] Polyphenols influence the metabolism of pro-carcinogens by modulating the expression of cytochrome P450 enzymes involved in their activation of carcinogens [11] [12].

To take advantage of the indicator properties of polyphenolic antioxidants, several polyphenolic derivatives were designed and synthesized and their color property at different $\mathrm{pH}$ have been studied.

To best of our knowledge, this is the first time these polyphenolic antioxidants are being reported as indicators for acid-base volumetric titration.

\section{Discussion}

The synthesis of triphenylmethanol derivatives $1 \mathrm{a}-\mathrm{k}$ was accomplished by using a modified method based on literature [13] [14] (Scheme 1). In this regard, 1,3,5-trioxane was added to a solution of phenol or anisol derivatives followed

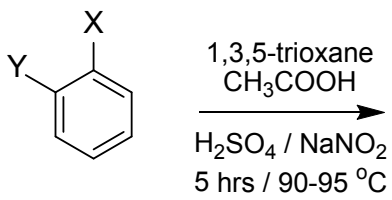

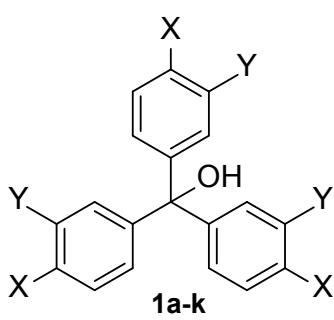

Scheme 1. Synthesis of triphenylmethanol derivatives $1 \mathrm{a}-\mathrm{k}$. 1a: $\mathrm{X}=\mathrm{OH}, \mathrm{Y}=\mathrm{COOH}$ 1b: $\mathrm{X}=\mathrm{OH}, \mathrm{Y}=\mathrm{COOCH}_{3}$ 1c: $\mathrm{X}=\mathrm{OCH}_{3}, \mathrm{Y}=\mathrm{OH}$ 1d: $\mathrm{X}=\mathrm{OCH}_{3}, \mathrm{Y}=\mathrm{F}$ 1e: $X=\mathrm{OCH}_{3}, Y=\mathrm{Cl}$ 1f: $\mathrm{X}=\mathrm{OCH}_{3}, \mathrm{Y}=\mathrm{Br}$ 1g: $\mathrm{X}=\mathrm{OCH}_{3}, \mathrm{Y}=\mathrm{CF}_{3}$ 1h: $\mathrm{X}=\mathrm{OCH}_{3}, \mathrm{Y}=\mathrm{CN}$ 1i: $\mathrm{X}=\mathrm{OCH}_{3}, \mathrm{Y}=\mathrm{CH}_{3}$ 1j: $\mathrm{X}=\mathrm{OCH}_{3}, \mathrm{Y}=\mathrm{OCH}_{3}$ 1k: $\mathrm{X}=\mathrm{OCH}_{3}, \mathrm{Y}=\mathrm{CHO}$ 
by heating of the mixtures. Then, a mixture of sulfuric acid in glacial acetic acid was added to the mixtures and the stirring of the solutions was continued. Finally, the reaction mixtures were cooled down and a solution of sodium nitrite and phenol or anisol derivatives in concentrated sulfuric acid were added to the reaction mixtures. The mixtures were then stirred at room temperature to give the triphenylmethanol $1 \mathrm{a}-\mathrm{k}$ derivatives which were further purified on CombiFlash Rf-200 chromatography to yield pure products (63\% - 87\%).

For the synthesis of tris(2-(hydroxymethyl)phenol derivatives, the reduction of 5,5',5"-(hydroxymethanetriyl)tris(2-hydroxybenzoic acid) (1a) in the presence of hydrogen $\left(\mathrm{H}_{2}\right)$ and palladium/charcoal afforded 5,5',5"-methanetriyltris (2-hydroxybenzoic acid) (2). Further reduction of 2 with a borane solution in THF gave 4,4',4"-methanetriyltris(2-(hydroxymethyl)phenol) (3). The reduction of (1b) with a suspension of $\mathrm{LiAlH}_{4}$ in THF produced 4,4',4"-(hydroxymethanetriyl)tris(2-(hydroxymethyl)phenol) (4). Scheme 2 illustrates the synthesis of tris(2-(hydroxymethyl)phenol) derivatives 3, 4.

The synthesized compounds $1 \mathrm{a}-\mathbf{k}, \mathbf{3}$ and $\mathbf{4}$ were then evaluated as indicators for the acid-base volumetric titration of a standard solution of $0.001 \mathrm{M} \mathrm{HCl}$ with a standard solution of $0.001 \mathrm{M} \mathrm{NaOH}$. The experiments showed a sharp color change of the solution from light yellow to light green at $\mathrm{pH}=6.44-7.08$ for $1 \mathrm{a}$, from light yellow to dark green at $\mathrm{pH}=6.59-8.18$ for $1 \mathrm{~b}$, from light violet to dark red at $\mathrm{pH}=6.56-7.82$ for $1 \mathrm{c}$, from light yellow to dark violet at $\mathrm{pH}=6.45$ 7.53 for $1 \mathrm{~d}$, from yellow to dark green at $\mathrm{pH}=6.87-8.24$ for $1 \mathrm{e}$, from orange to dark violet at $\mathrm{pH}=6.55-7.78$ for $1 \mathrm{f}$, from colorless to light red at $\mathrm{pH}=6.79$ 8.34 for $1 \mathrm{~g}$, from colorless to red at $\mathrm{pH}=7.02-7.53$ for $1 \mathrm{~h}$, from yellow to dark violet at $\mathrm{pH}=6.85-7.59$ for $1 \mathrm{i}$, from light violet to red at $\mathrm{pH}=7.24-7.78$ for $1 \mathrm{j}$, from colorless to blue violet at $\mathrm{pH}=6.70-7.86$ for $1 \mathrm{k}$, from dark orange to light yellow at $\mathrm{pH}=7.43-8.12$ for 3 and from dark red to light yellow at $\mathrm{pH}=6.45$ 7.23 for 4 . These indicators may have potential applications for acid-base titrations in a narrow range.<smiles>O=C(O)c1cc(C(c2ccc(O)c(C(=O)O)c2)c2ccc(O)c(C(=O)O)c2)ccc1O</smiles>

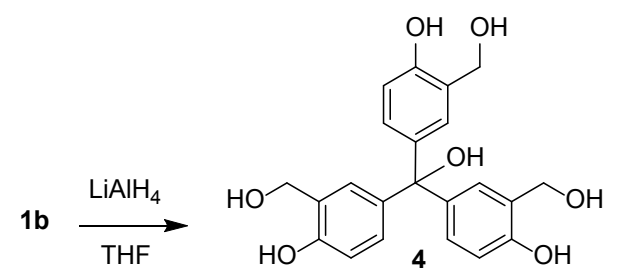

Scheme 2. Synthesis of triphenylmethanoltris(2-(hydroxymethyl)phenol derivatives 3, 4. 


\section{Experimental}

General Information: The chemical structures of products were characterized by a PE Biosystems Mariner API time-of-flight electrospray mass spectrometer. The volumetric titration with standard solutions of $0.001 \mathrm{M} \mathrm{NaOH}$ and $0.001 \mathrm{M}$ $\mathrm{HCl}$ were done at $25^{\circ} \mathrm{C}$ and pKa values were calculated by Henderson-Hasselbalch equation for the neutralization equilibrium point. The product yields for triphenylmethanol derivatives (1a-k) were calculated based on 1,3,5-trioxane starting material as a limiting reagent, i.e. the weight of pure isolated product was divided to the theoretical weight of the product assuming complete reaction and consumption of limiting reagent (trioxane) in course of the reaction.

\subsection{Preparation of Triphenylmethanol Derivatives (1a-k)}

1,3,5-trioxane (15 mmole) was added to salicylic acid, methyl salicylate, 2-methoxyphenol, 2-fluoroanisole, 2-chloroanisole, 2-bromoanisole, 2-(trifluoromethyl) anisole, 2-methoxybenzonitrile, 2-methylanisole, 1,2-dimethoxybenzene or 2-methoxybenzaldehyde solutions (100 mmole) in 10 $\mathrm{mL}$ glacial acetic acid. The mixtures were heated to reach to $90^{\circ} \mathrm{C}-95^{\circ} \mathrm{C}$, then 1 $\mathrm{mL}$ of a mixture of sulfuric acid: glacial acetic acid $(1: 5, \mathrm{v} / \mathrm{v})$ was added dropwise and the solution and the stirring were continued for $5 \mathrm{~h}$ at $90^{\circ} \mathrm{C}-96^{\circ} \mathrm{C}$. The reaction mixture was then cooled down to $0^{\circ} \mathrm{C}$ using an ice bath and a homogenous solution of sodium nitrite ( $1.0 \mathrm{~g}, 15 \mathrm{mmole})$ and salicylic acid, methyl salicylate, 2-methoxyphenol, 2-fluoroanisole, 2-chloroanisole, 2-bromoanisole, 2-(trifluoromethyl) anisole, 2-methoxybenzonitrile, 2-methylanisole, 1,2-dimethoxybenzene or 2-methoxybenzaldehyde (15 mmole) in $10 \mathrm{ml}$ concentrated sulfuric acid was added to the reaction mixture. The ice bath was removed and the stirring was continued at room temperature for an additional $24 \mathrm{hr}$. The mixture was then poured into crushed ice $(100 \mathrm{~g})$ with stirring. The precipitate was filtered off, dried under vacuum and was further purified on $\mathrm{C}_{18}$ column and hexanes/ethyl acetate as solvent using a TeledyneCombiFlash Rf-200 chromatography machine with the gradient system set at a constant flow rate of 25 $\mathrm{ml} / \mathrm{min}$ to yield pure products in $63 \%-87 \%$ yield. 5,5',5"-methanetriyltris (2-hydroxybenzoic acid) (1a) (4.43 g, 67\%), MS (ESI-TOF) (m/z) calcd. 441.1, found $441.2[\mathrm{M}+\mathrm{H}]^{+}$; trimethyl 5,5',5"-(hydroxymethanetriyl)

tris(2-hydroxybenzoate) (1b), (5.57 g, 77\%), MS (ESI-TOF) (m/z) calcd. 483.1, found 483.1 $[\mathrm{M}+\mathrm{H}]^{+}$; tris(3-hydroxy-4-methoxyphenyl)methanol (1c), (4.72 g, 79\%), MS (ESI-TOF) (m/z) calcd. 421.1, found $421.2[\mathrm{M}+\mathrm{Na}]^{+}$;

tris(3-fluoro-4-methoxyphenyl)methanol (1d), (3.83 g, 63\%), MS (ESI-TOF) $(\mathrm{m} / \mathrm{z})$ calcd. 405.1, found $405.0[\mathrm{M}+\mathrm{H}]^{+}$;

tris(3-chloro-4-methoxyphenyl)methanol (1e), (4.51 g, 66\%), MS (ESI-TOF) $(\mathrm{m} / \mathrm{z})$ calcd. 453.0 , found $452.9[\mathrm{M}+\mathrm{H}]^{+}$;

tris(3-bromo-4-methoxyphenyl)methanol (1f), (6.43 g, 73\%), MS (ESI-TOF) $(\mathrm{m} / \mathrm{z})$ calcd. 584.9 , found $584.9[\mathrm{M}+\mathrm{H}]^{+}$;

tris(3-trifluoromethyl-4-methoxyphenyl)methanol (1g), (5.91 g, 71\%), MS (ESI-TOF) (m/z) calcd. 555.1, found $555.1[\mathrm{M}+\mathrm{H}]^{+}$; 
tris(3-cyano-4-methoxyphenyl)methanol (1h) (4.59 g, 72\%), MS (ESI-TOF) $(\mathrm{m} / \mathrm{z})$ calcd. 448.1, found $448.0[\mathrm{M}+\mathrm{Na}]^{+}$;

tris(3-methyl-4-methoxyphenyl)methanol (1i), (4.77 g, 81\%), MS (ESI-TOF) (m/z) calcd. 415.2, found $415.3[\mathrm{M}+\mathrm{Na}]^{+}$; tris(3,4-dimethoxyphenyl)methanol (1j), (5.75 g, 87\%), MS (ESI-TOF) (m/z) calcd. 441.2, found $441.1[\mathrm{M}+\mathrm{H}]^{+}$; 5,5',5"-(hydroxymethanetriyl)tris(2-methoxybenzaldehyde) (1k), (4.37 g, 67\%), MS (ESI-TOF) (m/z) calcd. 457.1, found 457.1 [M+ Na $]^{+}$.

\subsection{Preparation of 5,5',5"-Methanetriyltris(2-Hydroxybenzoic Acid) (2)}

5,5',5"-(hydroxymethanetriyl)tris(2-hydroxybenzoic acid); (1) (2.20 gm, $5 \mathrm{mmol}$ ) was added into absolute ethanol $(50 \mathrm{~mL})$. Palladium/charcoal $(10 \%, 100 \mathrm{mg})$ was added to the solution and the mixture was shaken under hydrogen gas at $60 \mathrm{psi}$ using a hydrogenation apparatus for $96 \mathrm{~h}$. Then the Palladium/charcoal catalyst was filtered off using celite and washed with ethanol. The solvent of filtrate was removed under reduced pressure to yield

5,5',5"-methanetriyltris(2-hydroxybenzoic acid) (2) (1.89 g, 89\%). MS (ESI-TOF) $(\mathrm{m} / \mathrm{z})$ calcd. 425.0873 , found $425.0894[\mathrm{M}+\mathrm{H}]^{+}$, Melting point $280^{\circ} \mathrm{C}-282^{\circ} \mathrm{C}$. This dark red product was used for the next step of reaction without further purification.

\subsection{Preparation of 4,4',4"-Methanetriyltris(2-(Hydroxymethyl)Phenol) (3)}

5,5',5"-methanetriyltris(2-hydroxybenzoic acid) (2), (1.50 gm, $3.5 \mathrm{mmol}$ ) was dissolved in $50 \mathrm{~mL}$ THF under anhydrous condition [15] [16]. The solution which was equipped with a magnetic stirrer and ice bath, was cooled down to $0^{\circ} \mathrm{C}$ and then a $1 \mathrm{M}$ borane solution in THF $(45 \mathrm{~mL}, 45 \mathrm{mmol}$ ) was added dropwise over a period of $90 \mathrm{~min}$. After the completion of addition of $1 \mathrm{M}$ borane solution, the ice bath was removed, and the reaction mixture was allowed to warm up to room temperature. The resulting mixture was stirred for $1 \mathrm{hr}$ at room temperature and then was refluxed at $65^{\circ} \mathrm{C}$ for $3 \mathrm{hrs}$. At the end of which analysis of a small aliquot of the reaction mixture indicated the completion of the reaction. The reaction mixture was carefully quenched with $15 \mathrm{~mL}$ of water, concentrated by rotary evaporation, and then was made acidic with a $\mathrm{pH}$ of 6.5 by addition of $1 \mathrm{~N} \mathrm{HCl}$ and subsequently extracted with $\mathrm{Et}_{2} \mathrm{O}$. The organic layer was dried over $\mathrm{MgSO}_{4}$, filtered off and the solvent was removed by rotary evaporation. The product was isolated by flash chromatography on silica gel using EtOAc: $\mathrm{MeOH}(1: 1 \mathrm{v} / \mathrm{v})$ as eluent to yield pure 4,4',4"-methanetriyltris(2-(hydroxymethyl)phenol) (3) (1.02 g, 76\%). MS (ESI-TOF) (m/z) calcd. 383.1495, found $383.1612[\mathrm{M}+\mathrm{H}]^{+}$. The compound's color was pinkish red.

\subsection{Preparation of 4,4',4"-(Hydroxymethanetriyl)tris(2-(hydroxymethyl) phenol) 4}

A suspension of $\mathrm{LiAlH}_{4}(3.0 \mathrm{~g}, 80 \mathrm{mmol})$ in $50 \mathrm{~mL}$ anhydrous THF was pre- 
pared. The suspension was cooled down to $0^{\circ} \mathrm{C}$ using an ice bath. Then a solution of trimethyl 5,5',5"-(hydroxymethanetriyl)tris(2-hydroxybenzoate) (1b), (2 g, $4.15 \mathrm{mmol}$ ) in $50 \mathrm{~mL}$ anhydrous THF was added dropwise to the $\mathrm{LiAlH}_{4}$ solution during $1 \mathrm{~h}$ at $0^{\circ} \mathrm{C}$. Then the ice bath was removed and after reaching room temperature, the mixture was refluxed for $4 \mathrm{~h}$. The reaction mixture was then cooled to room temperature and quenched by the sequential addition of $3 \mathrm{~mL}$ of water, $15 \mathrm{~mL}$ of $10 \%$ sulfuric acid. Then the organic solvent was removed under vacuum and the residue was extracted using of diethyl ether $(3 \times 50 \mathrm{~mL})$. The combined filtrate was dried over anhydrous sodium sulphate and the solvent was removed under vacuum. The product was isolated by flash chromatography on silica gel using $\mathrm{Et}_{2} \mathrm{O}: \mathrm{MeOH}(1: 1 \mathrm{v} / \mathrm{v})$ as eluent to yield 4,4',4"-(hydroxymethanetriyl)tris(2-(hydroxymethyl)phenol) (4), (1.16 g, 70\%). The color of the product was dark red. MS (ESI-TOF) $(\mathrm{m} / \mathrm{z})$ calcd. 399.1444, found $399.1456[\mathrm{M}+\mathrm{H}]^{+}$.

\subsection{Volumetric Titration of a Standard Solution of $0.001 \mathrm{M} \mathrm{HCl}$ with a Standard Solution of $0.001 \mathrm{M} \mathrm{NaOH}$ Using (1a-k), (3) and (4) as Acid-Base Indicator}

The solutions of synthesized indicator compounds (1a-k), (3) and (4) were prepared by dissolving $0.25 \mathrm{~g}$ of each compound in ethanol to the final volume of 25 $\mathrm{mL}$ at room temperature followed by stirring for $10 \mathrm{~min}$. Then the indicator was poured into a $25 \mathrm{~mL}$ bottle fitted with an eye dropper. $25 \mathrm{~mL}$ of a standard solution of $0.001 \mathrm{M} \mathrm{HCl}$ was placed in a $100 \mathrm{~mL}$ Erlenmeyer flask and after addition of 4 - 6 drops of indicator (1a-k), (3) and (4) solution, the titration was started with a standard solution of $0.001 \mathrm{M} \mathrm{NaOH}$. The $\mathrm{pH}$ of $\mathrm{HCl}$ solution in the Erlenmeyer flask was carefully monitored with a Fisherbrand ${ }^{\mathrm{TM}}$ accumet $^{\mathrm{TM}}$ AB15 Basic $\mathrm{pH}$ Meter equipped with a conventional glass $\mathrm{pH}$ electrode during the titration. The color of the solution around the neutralization point was suddenly changed. Further increasing of the $\mathrm{pH}$ did not significantly change the color of the solution. The experiments were repeated 3 times for each compound.

\section{Results}

The triphenylmethanol derivatives are aromatic compounds, however in basic solutions, the aromaticity of phenolic rings is isolated. By decreasing the $\mathrm{pH}$ in acidic solutions, the hydroxy group of triphenylmethanol can absorb a proton and be eliminated from the molecule. The driving force for such a phenomenon is the chance of forming an integrated resonance system that is more stable. This phenomenon is responsible for changing the color in acidic and basic solutions. i.e. the isolated and integrated resonance systems absorb different wavelengths of light, therefore show different colors. Scheme 3 illustrates a mechanism of resonance structure conversion of triphenylmethanol derivatives $1 \mathbf{a}-\mathbf{k}$ in basic and acidic solutions. Similar mechanisms may apply to indicator 3 and 4.

Table 1 indicates the color change, $\mathrm{pH}$ range for the color transition and $\mathrm{pKa}$ values of indicator compounds (1a-k), (3) and (4). The pKa values were calculated 


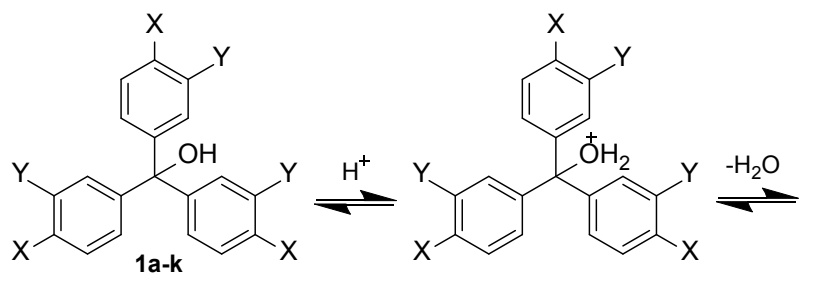

Isolated resonance system

(basic solutions)

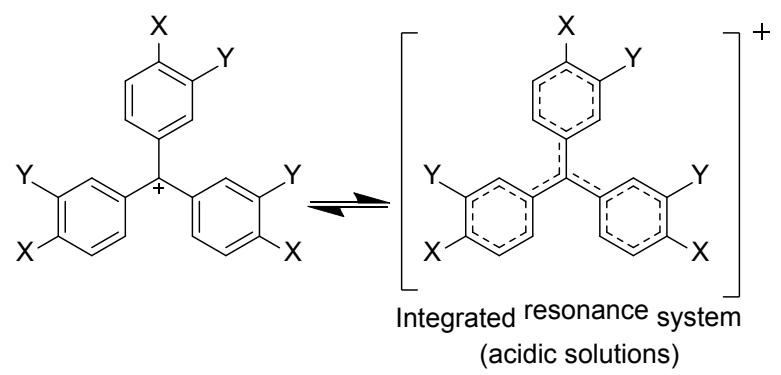

Scheme 3. Resonance structure of triphenylmethanol derivatives $1 \mathrm{a}-\mathbf{k}$ in basic and acidic solutions.

Table 1. Color change, $\mathrm{pH}$ range for the color transition and $\mathrm{pKa}$ values of indicator compounds 1a-k, 3 and 4 .

\begin{tabular}{cccc}
\hline Indicator & $\mathrm{pKa}$ & Color change & $\mathrm{pH}$ range \\
\hline $1 \mathrm{a}$ & 6.83 & Light yellow to light green & $6.44-7.08$ \\
$\mathbf{1 b}$ & 7.22 & Light yellow to dark green & $6.59-8.18$ \\
$1 \mathrm{c}$ & 7.57 & Light violet to dark red & $6.56-7.82$ \\
$\mathbf{1 d}$ & 6.93 & Light yellow to dark violet & $6.45-7.53$ \\
$1 \mathbf{l}$ & 7.56 & Yellow to dark green & $6.87-8.24$ \\
$\mathbf{1 f}$ & 7.34 & Orange to dark violet & $6.55-7.78$ \\
$\mathbf{1 g}$ & 8.12 & Colorless to light red & $6.79-8.34$ \\
$\mathbf{1 h}$ & 7.38 & Colorless to red & $7.02-7.53$ \\
$1 \mathbf{i}$ & 7.47 & Yellow to dark violet & $6.85-7.59$ \\
$1 \mathbf{j}$ & 7.21 & Light violet to red & $7.24-7.78$ \\
$\mathbf{1 k}$ & 6.95 & Colorless to blue violet & $6.70-7.86$ \\
$\mathbf{3}$ & 7.64 & Dark orange to light yellow & $7.43-8.12$ \\
4 & 6.86 & Dark red to light yellow & $6.45-7.23$ \\
\hline
\end{tabular}

according to Henderson-Hasselbalch equation for the neutralization equilibrium point at $25^{\circ} \mathrm{C}$. Table 1 shows the titration results and $\mathrm{pKa}$ values of indicators.

\section{Conclusion}

In summary, twelve triphenylmethanol and one tris(2-(hydroxymethyl)phenol derivatives were synthesized and tested as acid-base indicators. The experiments showed a sharp color change of the solutions near neutralization point for most 
indicators. These indicators may have potential applications for acid-base titrations in a narrow range.

\section{Acknowledgements}

We acknowledge the financial support from the National Cancer Institute, MMC-Vanderbilt-TSU Partners in Eliminating Cancer Disparities (MVTCP), Grant Number 5U54CA163066-03. We also acknowledge the financial support from the USDA National Institute of Food and Agriculture, Grant\# TENX-1608-FS. We thank US Department of Education, Title III Part B, grant number P031B090214 for partial financial support. Jawzah Alnakhli and Samiyah Alhamed acknowledge the scholarship provided by the Saudi Arabian Cultural Mission to the US (SACM).

\section{Conflicts of Interest}

The authors declare no conflicts of interest regarding the publication of this paper.

\section{References}

[1] Atkins, P.W. (1987) Molecules. W. H. Freeman, Oxford, England.

[2] Li, K.C. and Wagenknecht, A.C. (1956) Anthocyanin Pigments of Sour Cherries. Journal of the American Chemical Society, 78, 979-980. https://doi.org/10.1021/ja01586a029

[3] Francis, F.J., Harborne, J.B. and Barker, W. (1966) Anthocyanins in the Lowbush Blueberry, Vaccinium Angusifolium. Journal of Food Science, 31, 583-587. https://doi.org/10.1111/j.1365-2621.1966.tb01908.x

[4] Fuleki, T. (1969) The Anthocyanins of Strawberry, Rhubarb, Radish and Onion. Journal of Food Science, 34, 365-369. https://doi.org/10.1111/j.1365-2621.1969.tb10367.x

[5] Lukton, A., Chichester, C.O. and Mackinney, G. (1955) Characterization of a Second Pigment in Strawberries. Nature, 176, 790-792. https://doi.org/10.1038/176790a0

[6] Scalbert, A., Manach, C., Morand, C. and Remesy, C. (2005) Dietary Polyphenols and the Prevention of Diseases. Critical Reviews in Food Science and Nutrition, 45, 287-306. https://doi.org/10.1080/1040869059096

[7] Spencer, J.P., El Mohsen, M.M.A., Minihane, A.M. and Mathers, J.C. (2008) Biomarkers of the Intake of Dietary Polyphenols: Strengths, Limitations and Application in Nutrition Research. British Journal of Nutrition, 99, 12-22. https://doi.org/10.1017/S0007114507798938

[8] Bhooshan, P.K. and Rizv, S.I. (2009) Plant Polyphenols as Dietary Antioxidants in Human Health and Disease. Oxidative Medicine and Cellular Longevity, 2, 270-278. https://doi.org/10.4161/oxim.2.5.9498

[9] Yang, C.S., Landau, J.M., Huang, M.T. and Newmark, H.L. (2001) Inhibition of Carcinogenesis by Dietary Polyphenolic Compounds. Annual Review of Nutrition, 21, 381-406. https://doi.org/10.1146/annurev.nutr.21.1.381

[10] Johnson, I.T., Williamson, G. and Musk, S.R.R. (1994) Anticarcinogenic Factors in Plant Foods: A New Class of Nutrients? Nutrition Research Reviews, 7, 175-204. 
https://doi.org/10.1079/NRR19940011

[11] Talalay, P., De Long, M.J. and Prochaska, H.J. (1988) Identification of a Common Chemical Signal Regulating the Induction of Enzymes That Protect against Chemical Carcinogenesis. Proceedings of the National Academy of Sciences of the United States of America, 85, 8261-8265. https://doi.org/10.1073/pnas.85.21.8261

[12] Khan, N. and Mukhtar, H. (2008) Multitargeted Therapy of Cancer by Green Tea Polyphenols. Cancer Letters, 269, 269-280. https://doi.org/10.1016/j.canlet.2008.04.014

[13] Shrestha, S., Bhattarai, B.R., Chang, K.J., Lee, K.-H. and Cho, H. (2007) Methylenedisalicylic Acid Derivatives: New PTP1B Inhibitors that Confer Resistance to Diet-Induced Obesity. Bioorganic \& Medicinal Chemistry Letters, 17, 2760-2764. https://doi.org/10.1016/j.bmcl.2007.02.069

[14] Mark, C., Suseela, K., Erik, D.C., Dominique, S., Mark, E.G. and Julie, A.B. (1991) Synthesis and anti-HIV activities of low molecular weight aurintricarboxylic acid fragments and related compounds. Journal of Medicinal Chemistry, 34, 337-342. https://doi.org/10.1021/jm00105a053

[15] Brown, H.C., Heim, P. and Yoon, N.M. (1970) Selective Reductions. XV. Reaction of Diborane in Tetrahydrofuran with Selected Organic Compounds Containing Representative Functional Groups. Journal of the American Chemical Society, 92, 1637-1646. https://doi.org/10.1021/ja00709a037

[16] Yoon, N.M., Pak, C.S., Brown, H.C., Krishnamurthy, S. and Stocky, T.P. (1973) Selective Reductions. XIX. Rapid Reaction of Carboxylic Acids with Borane-Tetrahydrofuran. Remarkably Convenient Procedure for the Selective Conversion of Carboxylic Acids to the Corresponding Alcohols in the Presence of Other Functional Groups. The Journal of Organic Chemistry, 38, 2786-2792. https://doi.org/10.1021/jo00956a011 